\title{
Parliamentary Questions as an Instrument for Geographic Representation: The Hard Case of Portugal
}

\author{
Enrico Borghetto $^{1}$ (D) José Santana-Pereira $^{2}$ (iD and André Freire ${ }^{2}$ (iD \\ ${ }^{1}$ Nova University of Lisbon \\ ${ }^{2}$ ISCTE-IUL \& CIES-IUL
}

\begin{abstract}
This article asks whether and why, in a system lacking electoral incentives to cultivate personal votes, MPs might choose to signal to geographic constituents. It explores this question by analysing the number of written parliamentary questions submitted to the Portuguese parliament on two issues - unemployment and crime - between 2009 and 2015, and asking if MPs are more inclined to table questions on specific issues when their districts suffer particularly from related problems. The article finds evidence that constituency-level problem pressure does matter for the signalling activities of MPs, although policy specialization remains the main driver of their issue emphasis. This finding contributes new knowledge to the ongoing debate on the factors accounting for the representative relationship between MPs and constituents, by drawing attention to the importance of district-level problem pressure as one of the drivers of issue sponsorship in parliament.
\end{abstract}

Keywords: Parliamentary questions, geographic representation, issue attention, legislative behaviour, Portugal

\section{Introduction}

For a long time, legislative studies have been interested in understanding what drives the behaviour of members of parliament (MPs). Assuming that their primary motivation is to remain in office (Strøm 1997), MPs will seek to maximize their chances of holding on to their position by catering to the interests of those who decide the outcome of their election (Mansbridge 2003). Depending on the electoral rules (André et al. 2014a, b), MPs will have either more or fewer incentives to consider the concerns of their geographical constituents, and may therefore cultivate a personal vote. Having said that, whether institutional mechanisms encourage rather than determine specific courses of action and how these incentives play out and influence the responsiveness of MPs remains a question open to empirical investigation (e.g. Fernandes et al. 2019).

This article analyses the sources of the individual responsiveness of MPs towards geographic constituents by addressing whether and to what extent local problems affect the decisions of MPs to ask parliamentary questions on related issues. The dyadic relationship between MPs and their constituents has received much attention recently, both as a result of empirical findings on party heterogeneity (e.g. Itzkovitch-Malka and Hazan 2017) and as a reaction to the weakening of party loyalties and the growing 
disconnect between parties and voters (e.g. Mair 2013). Most of these studies focus on such personal vote-seeking strategies as providing particular 'pork barrel' policy benefits to a constituency or using parliamentary questions to address specific local issues. While also focusing on parliamentary questions, following Soroka et al. (2009) and Blidook and Kerby (2011), this article looks at their policy focus rather than at references to particular local entities: indeed, a considerable number of parliamentary questions have a national rather than a local focus, but this does not necessarily undermine their value as constituency signalling devices. Simply put, some problems need to be dealt with nationally rather than locally. The question we ask is if individual MPs perform constituency-focused legislative work by asking questions on specific issues when their district suffers particularly from those problems.

We focus on a least-likely country case, Portugal, where the closed-list proportional representation (PR) voting system ought to provide MPs with very little incentive to cultivate personal votes (Carey and Shugart 1995; Lisi and Santana-Pereira 2014). Here, the parties dominate political life and the links between MPs and their constituents are very weak. Nevertheless, the results of some important research has shown that even in party-dominated systems, MPs have some freedom of action from their parties (LestonBandeira 2009) and can engage in geographic representation without compromising party unity (Däubler 2018; Fernandes et al. 2017; Louwerse and Otjes 2016; Russo 2011; Zittel et al. 2019).

Here we measure issue focus in terms of the number of written parliamentary questions on two issues: unemployment and crime. We focus on written parliamentary questions because, unlike other forms of legislative activity in Portugal (legislative votes, oral questions to the Prime Minister and, to some extent, bill sponsorship) which are tightly controlled by the party, they provide some leeway that enables the MP to advance a personal agenda (Borghetto and Lisi 2018; Fernandes et al. 2017). Furthermore, there are no limits to the number of written questions an MP can raise, and drafting a question is less demanding than drafting a bill or a motion, which makes it an efficient way to respond to events quickly. Finally, while the policy impact of parliamentary questions is arguably limited, they are not entirely symbolic tools: they achieve their purpose to the extent ministers are forced to justify their actions or publish the information requested. All these attributes make written parliamentary questions an efficient channel for signalling attention to local constituents.

We analyse attention on unemployment and crime for a number of reasons. First, the availability of reliable and continuous indicators on these issues across districts. ${ }^{1}$ Second, politicians may be held accountable for a deteriorating performance on both fronts, so they are more likely to pay attention to variations in these statistics. Third, both are sensitive to "focusing events" (e.g. high-profile murders or massive layoffs) that may draw additional attention to the problem (Birkland 1998). Fourth, they represent issues that are traditionally owned both by parties on the left (unemployment) and the right (crime), thereby ensuring a reasonably broad coverage of Portugal's ideological spectrum.

\footnotetext{
${ }^{1}$ Although an analysis of the geographic distribution of recorded unemployed people and crime statistics is beyond the purview of the article, previous studies have noted that the economic geography of Portugal was, and still is, profoundly divided between communities near the coast and those in the interior (Syrett 2017). Arguably, these geographic divisions, which have been related to the recent boom in tourism, are associated with different levels of unemployment and crime across the country.
} 
To begin with, we investigate the link between geographic constituents and individual MPs by establishing whether there is a positive and significant correlation between problem pressure in distinct electoral districts (measured using annual local-level data) and the absolute number of parliamentary questions asked by those MPs elected in these districts. We then unravel the motivations behind this relationship by focusing on two sources of responsiveness: first, the political ties to the district (in terms of positions in either a local assembly or executive), in which we assume that the MPs' links to the local community imply they have stronger bonds with local interests, which should make signalling to constituencies more credible (Zittel et al. 2019); second, since parliaments and parties depend on a division of labour to legislate effectively and this encourages MPs to specialize on specific subjects, we expect MPs will ask more questions on issues that are problematic in their constituency when they fall within the remit of their assigned portfolio, which almost always coincides with their committee membership (Andeweg and Thomassen 2011).

This article is organized as follows. In the following section, we examine existing literature on the use of parliamentary questions by MPs as a way of signalling to their constituents and the factors that influence the probability of this behaviour to be observed, as well as other explanatory factors of policy topic focus in parliamentary questions. We then set out arguments and hypotheses and provide some background information on the Portuguese case, followed by a section introducing our data and outlining our methodological approach. The article concludes with a discussion of the main empirical patterns observed and their implications for the discussion on personal sources of responsiveness.

\section{Geographic Representation as Signalling Behaviour Through Parliamentary Questions}

Parliamentary work often takes the form of policy advocacy, with MPs advocating on behalf of policies (Bertelli and Dolan 2009). However, entities being represented by MPs policy advocacy behavior, whose demands they wish to represent, may vary. Carey (2007) argues that political parties and electoral constituencies are the two most important actors competing for the attention of MPs. This results in two ideal-type forms of representation: partisan representation, which 'portrays legislators as members of teams that collectively represent socially-cohesive national coalitions of voters'; and dyadic representation, which views MPs 'as individual agents accountable to local, and thus geographically-defined, constituencies' (Zittel et al. 2019: 682).

In western European parliamentary democracies, parties tend to be the main focus, with the extent to which constituencies can compete for the attention of MPs being dependent on several factors (see Fernandes et al. 2019; Zittel et al. 2019). As Däubler eloquently puts it:

'MPs may want to work especially on issues important to the party constituency because: (1) they find these issues important per se; (2) they are in closer contact with party constituents than with other parts of the citizenry; (3) the candidate selectorate strongly cares about these matters; or (4) citizens may vote for the party or the candidate as a reward for tackling those issues. (Däubler 2018: 4).

We argue that the same set of reasons can be used in the analysis of the local focus of legislative work, and we test this assumption through the lens of questioning activity. But 
how can MPs use parliamentary questions to signal their geographic constituencies that they are indeed representing them? The literature provides two possible responses: a reference to the constituency in the tabled questions, or a focus on topics that are of particular importance to the geographic constituencies they represent.

Studies operationalizing constituency focus as a direct or implicit reference to the constituency in the parliamentary question have mapped this phenomenon and sought to identify those factors that impact the probability of adopting such a focus. The electoral system (namely whether ballot structures grant voters freedom to cast personal votes) is believed to be important, with constituency-focused questions being more common in Ireland than in Italy (2006-08), for example (Martin 2011; Russo 2011). However, electoral institutions are only part of the story, since even in a context in which the electoral system rules should not create incentives for MPs to cultivate personal votes, such as in Italy (2006-08), one-third of parliamentary questions were constituency-focused (Russo 2011).

The electoral vulnerability of MPs is also thought to be a key element. In Italy, MPs with prominent leadership roles, who are therefore less vulnerable electorally, are less willing to perform constituency service, since it will not necessarily improve their chances of being reselected by their parties (Russo 2011). A recent study on Portugal by Fernandes et al. (2017) found that electoral vulnerability has an impact on the focus of representation (distinguishing between district and party-focused parliamentary questions), but only if analysed in association with the moment in the electoral cycle and the size of the party. However, this is not the case in either the United Kingdom or Ireland, where the electoral vulnerability of parliamentary representatives is not associated with a difference in the likelihood of raising constituency-focused questions (Kellermann 2016; Martin 2011). In a more recent study, Fernandes et al. (2019) distinguish constituency-focused questions from trustee-style questions (independent from party or district considerations) and show that electoral vulnerability increases the likelihood of MPs tabling the former in Portugal and Germany, but encourages the latter in Ireland. In a study measuring vulnerability as the degree of electoral volatility linked with the existence of large numbers of non-partisan voters at the district level, Zittel et al. (2019) note that MPs competing in more volatile constituencies display a greater tendency to table written questions containing geographic references.

The government versus opposition status is also believed to be a factor, although in this respect the results are inconsistent: in Italy and Germany, MPs from (some) opposition parties are more likely to adopt a local focus (Russo 2011; Zittel et al. 2019), while parliamentary representatives of the governing party in Ireland are more likely to raise questions that focus on their constituencies (Martin 2011). Members of the European Parliament from domestic opposition parties are more likely to notify the European Commission of violations of EU law in their member states (their constituencies) than MPs from the national parties of government (Jensen et al. 2013). Among other important variables underlined by these studies, we find: the nature of the political party (parties not claiming to be national with an electorate concentrated in a specific region are more likely to adopt a constituency focus) (Russo 2011); the position of the electoral district in the centre-periphery cleavage (MPs from peripheral districts tend to adopt a more constituency focus) (Martin 2011); or the centralization of the candidate selection process (the more centralized candidate selection is, the less likely it is that MPs will focus on the interests of their districts, with this effect being stronger in Portugal than in Ireland or Germany) (Fernandes et al. 2019).

There is currently a small, but growing, number of studies investigating this form of geographic representation in a different way, by focusing on the interplay between district 
specificities and preferences on the one hand, and the content of questions on the other. For instance, Saalfeld (2011) noted that in the UK, MPs representing constituencies with a greater presence of visible minorities will ask more questions about diversity and immigration. In a subsequent study corroborating this finding, Saalfeld and Bischof (2013) noted that all British MPs, regardless of their own ethnic background, are responsive to the interests of minority constituents when these are geographically concentrated. In Canada, Soroka et al. (2009) and Blidook and Kerby (2011) studied the link between a series of constituency characteristics and preferences and the extent to which questions tabled by MPs elected in those constituencies mirror these concerns. The authors observe that such representation is commonly observed, even though it varies from issue to issue, and often (but not always) MPs facing electoral pressure, or vulnerability (narrow victory margins), are more prone to engage in this mode of constituency representation via questions. Other factors that may have an impact on the constituency focus of a specific topic by parliamentary questions are media coverage (Vliegenthart et al. 2016), the gender and social identity of MPs (Bird 2005; Saalfeld 2011) or considerations of intra-party competition (Bevan and John 2016).

While existing research shows parliamentary questions are often used to signal efforts aimed at representing geographic constituencies, most factors explaining the probability of engaging in such behaviour deal with the electoral system and/or strategic and electoral considerations (those related with reasons 3 and 4 Däubler (2018) uses to explain the MPs' focus), leaving the role of personal sources in this process largely ignored (Däubler's reasons 1 and 2, concerning interest and proximity). The existing literature provides direct and indirect support for both factors, which may moderate the link between constituency characteristics and issue focus of parliamentary questions. First, the existence of powerful links between the MPs and their constituency encourages this behaviour: in Italy, MPs who are parachuted into districts tend to be less focused on the constituencies than those who were born and who live in the constituency (Russo 2011); while in Germany both biographical localness (MPs who were born, educated and who live in the district) and political localness (MPs who exercised executive or legislative roles within the district) increases the odds of tabling questions with a reference to the electoral district (Zittel et al. 2019). Second, since MPs table questions that tend to be within the jurisdiction of the committees they belong to (Kellermann 2013; Proksch and Slapin 2010) or the portfolios or shadow portfolios they hold within their parliamentary party group (Soroka et al. 2009), expertise may also be a key moderating variable of constituency-relevant issue focus.

\section{Attending to Constituency Interests: The Responsiveness to Problem Pressure and the Mediation of Personal Characteristics}

The following analysis aims at testing whether and to what extent MPs use written parliamentary questions to cater to constituency interests. But how do we tap into the elusive concept of interests? Arguably, a highly valid measurement would be to survey a sample of citizens from each constituency about their views on the most important problem affecting their community and build a profile of the local average voter (Waggoner 2019). ${ }^{2}$ Indeed, as Wlezien notes, one should distinguish the salience (or prominence) of an issue from whether it

\footnotetext{
${ }^{2}$ Using public survey data is not without its own problems: first, the preferences of constituents may be unstable and to some extent built on poor information (Fowler and Margolis 2014); second, existing surveys are often blind to temporal and geographic variations.
} 
is perceived to be a problem. More specifically, an issue becomes a problem 'when conditions are worse than people would like' (Wlezien 2005: 560).

In the absence of these direct measurements of voters' perceptions, we chose to build indicators of local problem pressure using available local data on the incidence of unemployment and crime. ${ }^{3}$ Four criteria led to the selection of the two issues. First, both issues generate a continuous flow of problem information in the form of official municipal statistics, allowing tracking variation in problem pressure across both time and districts. Second, both issues are still largely dealt with at the national and local level, rather than at the supranational level, so national politicians are likely to be held accountable for not addressing the problem. Third, both are sensitive to the occasional focusing event (Birkland 1998), which attracts media and voters' attention and make problems leap into sudden prominence (e.g. a massive layoff in a big industry or the emergence of a corruption scandal among civil servants). Having said that, one should be aware that the relative perception of 'unemployment" and 'crime' as problems differs in Portugal. ${ }^{4}$ Whereas unemployment has typically ranked at the top of Portuguese voters' concerns - especially during the years covered in this study which saw the peak of the Euro crisis - the country has traditionally boasted a relatively low crime rate. As a result, we should expect politicians to be, on average, more responsive to variations in unemployment rates. Finally, the two issues appeal to different sides of the ideological spectrum, which helps ensure our findings are more generalizable. Drawing on classic theories in the literature of political sociology (e.g. Lipset and Rokkan 1967) and issue competition (e.g. Robertson 1976), the issue of unemployment is traditionally "owned" by left-wing parties, while crime and order is "owned" by the right.

Our main hypothesis states that MPs ask questions that are either unemployment or crimerelated when indicators on these two issues in their district get worse. First, signalling attention to their geographic constituents is aimed at enhancing their party's electoral appeal, in addition to other partisan vote-getting strategies. Certain re-election-seeking MPs may also act under the assumption that such activities are valued by party elites and get rewarded with a high position in the electoral list. Second, the importance of privileged communication links with the constituency should not be understated in relation to parliamentary questions, since it is common for local actors to write the text of the question, then pass it to their MP, who then signs and submits it on their behalf. As a result, our first hypothesis reads as follows:

H1 - The stronger the problem pressure in the district where MPs were elected, the more questions they will ask about it.

In an effort to tease out the drivers behind the constituency-focused behaviour of MPs, we test the moderating effect of two MPs' traits. Both should increase the incentives for

\footnotetext{
${ }^{3}$ This is an indirect measure of issue salience in the constituency similar to that used by Waggoner (2019). Interestingly, while he reports no consistent direct impact of constituent preferences, measured via survey data, on the content of bill sponsorship, he detects an impact of district characteristics, measured as the percentage of constituents working in specific sectors.

${ }^{4}$ An appreciation of the relative importance of 'unemployment' and 'crime' can be obtained by using the responses to the 'Most Important Problem' question that is asked periodically by the Eurobarometer (see Online Appendix B). In Portugal between 2009 and 2017, unemployment is considered by far the most important issue facing the country: one respondent in every two puts this issue at the top of the list (average proportion of $51 \%$ and a standard deviation [SD] of $22 \%$ ). In the wake of the sovereign debt crisis in Portugal that led to the signing of the financial assistance programme, its importance rose as high as $90 \%$ (2010-2012). As for crime, it is mentioned on average by $14 \%$ of the Portuguese respondents (with a SD of $6 \%$ ), placing it in seventh position during the period considered (after economic concerns $-34 \%$, inflation $-21 \%$, immigration $-18 \%$, health and social security $-17 \%$ and government debt $-15 \%$ ).
} 
the MP to invest in signalling constituency-bound strategies. First, we consider whether the MP has in the past served in the constituency (André et al. 2014a; Shugart et al. 2005). ${ }^{5}$ Our expectation is that MPs who have served in the district will develop both stronger ties with the constituency and expertise on local matters, and that they will be therefore more likely to present themselves as problem-solvers and focus on issues that are important to the district (Zittel et al. 2019). Second, it might be in the interest of party elites to use these 'local' MPs as their special and most visible liaisons with the district. Indeed, Fernandes et al. (2017: 682) already found that in Portugal, "representatives with local government positions have a higher likelihood of tabling questions for both their party and their district". Of course, we acknowledge that such a relationship is built on public speeches, media appearances and constituency visits, but parliamentary questions can also be considered one such channel. As a result, we expect that:

H2 - MPs who served as local representatives in their districts should table more questions on issues related to unemployment and crime in response to their district's problem pressure.

As we have seen above, in both national and supranational parliaments it is often the case that policy specialization affects the topics MPs choose to tackle in their parliamentary questions (Kellermann 2013; Proksch and Slapin 2010). As a result, we take into consideration a MP's policy specialization as a moderating factor in the relationship between constituency-level problem pressure and the number of parliamentary questions about those issues. Both parliaments and parties benefit from an internal division of labour, where individual MPs develop expertise over specific policy areas (Krehbiel 1991). From the point of view of internal organization, this translates into the assignment of specific policy portfolios to MPs, which often mirrors their committee membership (Martin 2014). Consequently, we posit that membership in a relevant committee should be a strong predictor of the number of questions MPs table on unemployment and crime when these are relevant concerns in their districts. What is more, we assume that such a division of labour should be particularly strict in a party-dominated system such as Portugal, where MPs are party delegates first and foremost. We therefore expect that:

H3 - MPs who sit in committees with a relevant policy jurisdiction over unemployment and crime should table more questions on these issues in response to their district's problem pressure.

\section{The Personal Sources of Responsiveness in a Party-Dominated System: The Case of Portugal}

The goal of this section is to briefly outline the main characteristics of the Portuguese parliamentary system and justify why, while it represents a case which is unlikely to exhibit geographic representation, there is still reason to expect some level of geographic signalling as a party-led strategy.

Portugal has a single chamber of 230 MPs elected to a four-year legislature. The country is divided into 22 electoral districts - 18 mainland administrative districts, two autonomous regions (Azores and Madeira) plus two districts for Portuguese living abroad (European and rest-of-the-world districts). Four parties have been consistently represented

\footnotetext{
${ }^{5}$ According to the Statute of Members of the Portuguese Parliament (Art. 20), the job of MP is incompatible with other positions in local and executive assemblies.
} 
in parliament since the early 1980s (five if we include the Left Bloc from the late 1990s), making it one of the most stable party systems in Europe (Leston-Bandeira and Freire 2003). Starting from the far left of the political spectrum, we find the coalition between the Communist (PCP) and the Green (PEV) party, together with the Left Bloc (BE). Both won around $10 \%$ of the seats in the 2015 elections and, for the first time, decided to offer external support to a minority Socialist government, based upon three written parliamentary agreements. The centre-left is occupied by the Socialist Party (PS), while on the right and the centre-right, respectively, are two parties that often govern in coalition, the smaller People's Party (CDS-PP) and the Social Democratic Party (PSD).

We argue that Portugal is a least-likely case for testing the presence of geographic representation in a strong party-dominated system. First, the closed-list PR system used in Portuguese legislative elections create fewer incentives for MPs to cultivate personal votes (Carey and Shugart 1995; Lisi and Santana-Pereira 2014) and, therefore, to focus on issues that are salient to the constituency. This makes Portugal a rather robust setting in which to test district-level determinants of MPs' behaviour as opposed to countries adopting preferential voting systems.

However, despite this institutional framework, it has been shown that there is significant intra-system variation in terms of constituency focus (looking at attitudinal focus and hours spent in the constituency compared to time spent in parliament). Specifically, the latter is negatively correlated with the district magnitude (Freire et al. 2017; Pilet et al. 2012). Second, Portuguese parties tend to display a centralized system for candidate selection, one in which the national party elites play a very powerful role (Teixeira et al. 2012). However, there are still differences between the parties. The PSD is the least centralized party for candidate selection, while the PCP is the more centralized party. The other parties (BE, PS and CDS-PP) lie somewhere between the two extremes.

\section{Data and Methods}

The empirical analysis relies on a data set that combines information on the topic of all written parliamentary questions ('perguntas ao governo') submitted by Portuguese MPs during the eleventh (2009-2011) and twelfth (2011-2015) legislatures, biographies of those asking the questions and statistics on the problem pressure of crime and unemployment at the constituency level (see Table 1 for a summary of variables). ${ }^{6}$

\section{Dependent Variable}

Our two dependent variables are the absolute number of questions asked by an MP on issues related to crime and unemployment. In Portugal, there are no detailed regulations concerning the tabling of written parliamentary questions. The Constitution stipulates that MPs have the authority to "ask questions to the government or to the public administration about any of its activities and receive an answer within a reasonable time, with the exception of matters concerning state secrecy" (Article 156d). However, while written questions (perguntas ao governo) have existed since 1976 (not only in the constitution, but also in the first draft of the Procedural Rules), they were rarely used

\footnotetext{
${ }^{6}$ Data about biographies and parliamentary questions were retrieved from the parliament's official website, www.parlamento.pt.
} 
Table 1: Description of Variables Included in the Model Predicting the Number of Questions on Unemployment and Crime

\begin{tabular}{|c|c|}
\hline Variable & Description \\
\hline \multicolumn{2}{|l|}{ Dependent variables } \\
\hline \multicolumn{2}{|c|}{$\begin{array}{l}\text { Absolute number of parliamentary questions on the topic of unemployment and crime signed by the } \\
\text { MP as first sponsor }\end{array}$} \\
\hline \multicolumn{2}{|c|}{ Independent variables } \\
\hline \multirow[t]{4}{*}{ Problem pressure } & Across district \\
\hline & 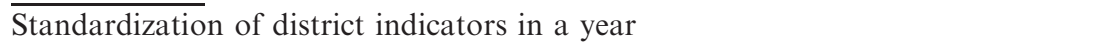 \\
\hline & Across time \\
\hline & Percent change of the indicator using the previous year as baseline \\
\hline MP localness & $\begin{array}{l}1 \text { if member of local assembly, executive or mayor before entering parliament; } 0 \\
\text { - otherwise }\end{array}$ \\
\hline Committee & $\begin{array}{l}1 \text { if member of the relevant committee for the topic during the legislature; } \\
0 \text { - otherwise }\end{array}$ \\
\hline \multicolumn{2}{|l|}{ Controls } \\
\hline Magnitude & Number of seats assigned in the electoral district (values are log transformed) \\
\hline $\begin{array}{l}\text { Mandates in } \\
\text { district }\end{array}$ & $\begin{array}{l}\text { Absolute number of terms won by the MP in the electoral district when } \\
\text { he/she was elected }\end{array}$ \\
\hline Vulnerability & $\begin{array}{l}\text { Ratio between the position that the candidate MP holds in the party list and } \\
\text { the number of seats won in that district by the MP's party }\end{array}$ \\
\hline Gender & $0=$ Male, $1=$ Female \\
\hline Opposition & $0=$ Government, 1 = Opposition \\
\hline Party & Party of the MP (reference is PS) \\
\hline
\end{tabular}

during the first 20 years. Prior to 2007, this instrument was largely discredited because the cabinet member receiving the questions could decide which of them to answer (LestonBandeira 2004). There was also a limit to the number of questions each group could submit. Unanswered questions were periodically published in parliament's Official Journal, but there was little expectation that ministers would actually respond to them. However, this changed in 2007 (Seguro 2016) when a reform turned this instrument and the request for information (requerimento) into the two most widely used procedures. ${ }^{7}$ Currently, the government is obliged to respond within 30 days and, should this deadline be missed, the question gets published in the Official Journal as a reminder.

Interviews with MPs confirm that, for the most part, they are not constrained by party leaders when drafting and submitting written questions to the government (Borghetto and Lisi 2018; Fernandes et al. 2017). Yet, this does not mean the party does not monitor the process, rather it means that within these boundaries, MPs are free to direct attention to their favourite topics. The question asked here is whether they also use these questions to send signals to their constituencies.

In practical terms, we attribute a question to an MP only if they are the first signatory (more than one party member can be asked to sign a question). While there are no formal rules regarding the order of signatories, when asked, MPs confirm that the initiator and author of the question is generally the first named (Borghetto and Lisi 2018). Additionally,

\footnotetext{
${ }^{7}$ While "questions to the government" (perguntas ao governo) are instruments of political control that can only be addressed to government ministers and (less often) senior public officials, "requests for information" (requerimentos) are information gathering tools that can be directed to national and local public officials.
} 
there are concerns on whether co-signing a question represents a demonstration of interest for the topic or whether it is simply a favour for a party colleague. Given this, here we consider only first signatories.

Our unit of analysis is the MP/session dyad (the full legislative term is split into four one-year sessions that ordinarily begin in September). Since some MPs are substituted either temporarily (for example, because of an extended leave) or permanently (230 MPs are elected to sit in the Portuguese parliament but a total of 313 MPs served during the twelfth legislature) during the course of the legislature and with the amount of time spent in parliament affecting the likelihood of asking a question, we filtered out those who were not present during the entire legislative session. We also removed representatives from the Green party and the People-Animals-Nature parties (their party groups have less than 3 members) and those elected in the European and rest-of-the-world districts. The final data set includes 345 individual MPs, each observed on average across four sessions, with a presence across legislatures as follows: 222 MPs in the eleventh legislature and 253 in the twelfth. Figures may be higher than 230 because some parliamentary groups (especially the $\mathrm{BE}$ and PCP) substitute a portion of their MPs halfway through the session. Given that we cover 6 legislative sessions and that there are roughly 210 MPs in each, there are 1265 observations in our sample.

Our complete data set contains 10997 questions: 4315 in the two-year eleventh legislature and 6682 in the four-year twelfth legislature. Even after filtering out duplicate questions (for instance, the same question may be asked three times on the same day when addressed to three ministers), ${ }^{8}$ parties are responsible for a different proportion of questions: almost two-third of all questions were submitted by the PCP $(42 \%)$ and the BE $(23 \%)$, while the remaining questions were shared equally among the PS, PSD and CDSPP (each with approximately 11\%). At the individual level, PCP and BE MPs ask an average of 63 and 46 questions, respectively, per session. The figures for the other parties are much lower, with three from the PS, two from the PSD and ten from the CDS-PP. Overall, representatives from smaller parties have greater incentives to gain visibility by acting as a cabinet watchdog.

The main policy content of each question was classified according to one of the 217 categories of the Portuguese policy agenda codebook (www.comparativeagendas.ne t/portugal) (Belchior and Borghetto 2019). Coding reliability was assured by having two coders blind-coding the same document simultaneously. ${ }^{9}$ The two selected topics - crime and unemployment - correspond to different combinations of policy agenda codes (see Online Appendix A for more information). Note that not all questions should explicitly address cases of either unlawful layoffs or criminal offences. We decided to cast our net wider to capture all instances of activity loosely related to our two issues (e.g. problems of low salaries in a call centre or personnel issue in Portuguese prisons), since they can still be taken as a signal to constituents that their MP, on behalf of the party, is taking a position on issues that are important in the district. We consider this a conservative approach since it provides a bias against finding the hypothesized link.

Figure 1 illustrates the distribution of questions across topics and parties. Over the course of our six-year period, MPs asked 739 questions related to unemployment $(6.7 \%)$

\footnotetext{
${ }^{8}$ Three criteria have to be simultaneously present to categorize a question as duplicated: it has a similar title, it is presented on the same day and it has the same author as another.

${ }^{9}$ The average intercoder reliability was around $80 \%$ and the remaining differences in coding decisions were resolved through discussion. In case of disagreement between the coders, the authors made the final decision.
} 
Figure 1: Distribution of Parliamentary Questions Across Parties and Topics During the $11^{\text {th }}$ and $12^{\text {th }}$ Legislatures
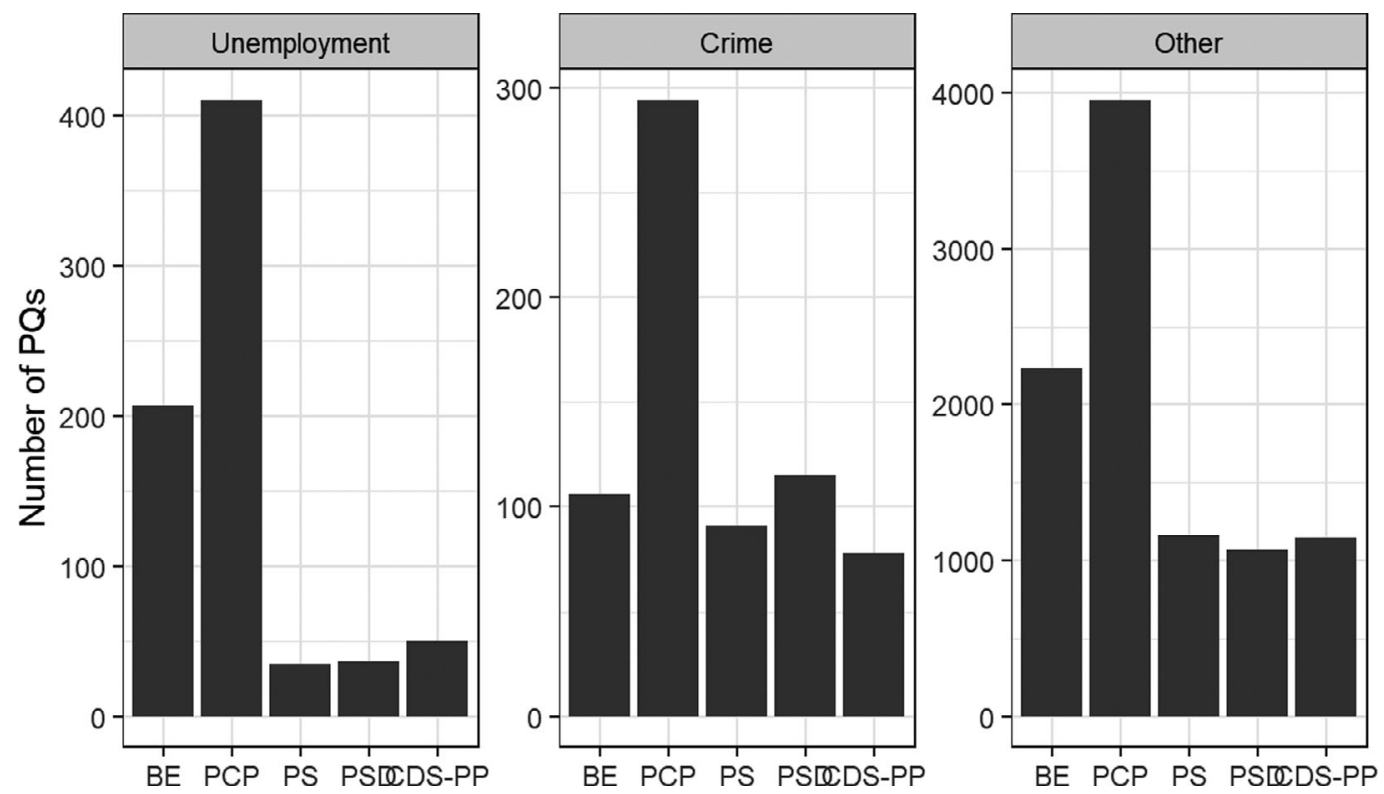

Source: Own data.

and 684 related to the area of crime $(6.2 \%)$. While PCP and BE representatives always ask more questions than MPs from other parties, this gap is wider on matters of unemployment, which is historically their signature issue (Lisi 2015). Out of all the MPs in our sample $(n=345)$, around $75 \%(n=259)$ asked at least one question. Of this subgroup, $41 \%(n=107)$ and $33 \%(n=85)$, respectively, asked at least one question related to either crime or unemployment, which is indicative of the popularity of these topics among MPs. On the other hand, we should mention that the distribution of questions is fairly skewed because of a small number of hyperactive BE and PCP MPs. ${ }^{10}$

\section{Problem Pressure, Political Localness and Committee Membership}

After a careful examination of Portuguese local data indicators available on a yearly basis and spanning the period 2009 to 2015, we decided to focus on two statistical indicators available at the municipal level: the share of unemployed people aged 15 to 64 registered with the public employment office; and the number of registered crimes per thousand inhabitants. To construct the two versions of our problem pressure variable, ${ }^{11}$ we first attributed yearly indicators to the year in which the legislative session started. This was because our dependent variable is aggregated by legislative sessions and our social indicators are available by calendar year. This meant that data from 2009 were used to

\footnotetext{
${ }^{10}$ Descriptive statistics are as follows. For unemployment, mean: 9, SD: 20, min: 1, max: 129. For crime, mean: 6, SD: 12, min: 1, max: 102 .

${ }^{11}$ See Online Appendix C for more information on the construction of the two problem pressure variables.
} 
predict behaviour during the first parliamentary session starting in 2009 (running from 15 October 2009 to 15 September 2010), data from 2010 were applied to the 2010 parliamentary session and so on for the remaining sessions. By doing this we created a temporal lag between the publication of the statistics and our measurement of parliamentary activity.

We then constructed our two problem pressure indicators. Although the concept of problem pressure may sound intuitive, its measurement is not straightforward because it needs a yardstick against which the current situation can be measured. In the analysis that follows, we have built on two assumptions about how MPs process information about social problems such as crime and unemployment and draw conclusions as to the severity of the situation. First, they can compare the situation in their district with the average district. Second, they can compare current and past district conditions. These correspond to two versions of our "problem pressure" variable, which we label "across district" and "across time". Notice that we are not assuming every MP will perform both types of comparison - most often they make decisions based on poor information - and we do have no expectations about their policy-specific effect. On the other hand, lacking a microlevel theory of agenda-setting, we think it is important to consider both perspectives. The two variables were constructed as follows:

(a) Across district. We standardized all district-specific indicators in a year. We first calculated the mean and standard deviation using all district values in a year, then we subtracted the indicator observed in a district in a year from the yearly mean and divided it by the yearly standard deviation.

(b) Across time. For the same district we calculated the difference between indicators in $t_{-1}$ and $t_{0}$, then divided it by the indicator in $t_{-1}$ and multiplied it by 100 . If the resulting figure is positive (negative) it means there was an increase (decrease) with respect to the previous year. For example, the percent change from the year 2009 to year 2010 was used to predict legislative activity during the first legislative session starting in October 2009.

While $\mathrm{H} 1$ tests the net effect of district problem pressure on the number of questions about that policy area, $\mathrm{H} 2$ and $\mathrm{H} 3$ look at the conditioning effect of political localness and committee membership. To test $\mathrm{H} 2$, we created a dummy, taking the value of 1 if the MP had in the past served as either a mayor or as member of the local executive/assembly. This categorization of MPs is based on their self-authored profiles published on the Portuguese parliament's website. To test H3, we proceeded in two steps. First, we detected whether the MP belonged either to the "Committee on Work and Social Security" (Comissão de Trabalho e Segurança Social) for matters related to unemployment, or to the "Committee on Constitutional Affairs, Rights, Freedoms and Guarantees" (Comissão de Assuntos Constitucionais, Direitos, Liberdades e Garantias) for matters related to crime. Second, since district characteristics can drive either the self-selection or party-selection of committee membership, we included the committee variable after purging the effects of local-level unemployment and crime statistics. ${ }^{12}$

\footnotetext{
${ }^{12}$ First we regressed committee membership on problem pressure indicators, then we incorporated the stored residuals as the new committee variables in our main model (see e.g. Waggoner 2019).
} 


\section{Control Variables}

We included a battery of control variables that were found to have an effect on the likelihood of asking a parliamentary question (regardless of the topic) in previous analyses. The variable "magnitude" measures the number of MPs elected within each constituency. District magnitude in Portugal varies significantly, ranging from Portalegre, which elects two MPs, to Lisbon, which elects $47 .^{13}$ The literature on the relationship between electoral system characteristics and dyadic representation (Carey and Shugart 1995) suggests that, in closed list systems, incentives to cultivate personal votes increase with decreasing district magnitude, which may translate into more constituency-focused questions. Electoral vulnerability measures the degree of uncertainty each MP feels about the prospect of their re-election. Because of the closed-list proportional system in use in Portugal, we follow André et al. (2015) and measure vulnerability as the ratio between the position the candidate has on the party list and the number of seats won in that district by the candidate's party in the most recent election. For example, the candidate who is second on a party list winning five seats receives a ratio of 0.4 , while the ratio for the candidate named fifth on that same list is 1. According to some authors (Fernandes et al. 2017; Russo 2011; Soroka et al. 2009), although not to others (Kellermann 2016; Martin 2011), electoral vulnerability should correlate positively with the likelihood of asking a question: vulnerable MPs should have a greater incentive to use parliamentary activities to improve their position on the list and increase their chances of re-election. 'Mandates in district" measures the absolute number of times an MP was elected in that constituency. These are candidates who have strong local roots and visibility and who have a reputation that is consolidated in the opinion of both party leaders and voters. As a result of their electoral safety, they may often feel less of an incentive to direct their efforts towards parliamentary questions, leaving this to other less institutionalized MPs.

'Opposition' is a dummy variable that equals 1 if the MP was member of an opposition party and 0 otherwise. Since getting information from or influencing the agenda of members of the executive through more informal means is generally more difficult for opposition MPs, they should rely more heavily on parliamentary questions. Next, we control for the MP's gender (1 if female) since, based on previous works (Bird 2005), we expect women MPs to tend to focus more on social policy-related themes (family policy, care for the elderly, health care). Finally, we included a categorical variable to capture the MP's party membership (reference value is PS) as a means of dealing with all the remaining party-related variables.

The choice of the statistical model for our analysis was driven by two characteristics of our data. First, the count of sponsored written questions is an integer featuring high overdispersion (i.e. the conditional variance exceeds the conditional mean). Second, our data are organized as an unbalanced panel with observation for the same MP spread over multiple legislative sessions. This might result in correlated outcomes for the same MP, thus affecting coefficients. As a result, we fitted a hierarchical negative binomial model with random intercepts for each MP. ${ }^{14}$

\footnotetext{
${ }^{13}$ Since we do not expect a linear relationship between district magnitude and the likelihood to ask a question, we transformed district magnitude using the logarithmic function.

${ }^{14}$ A comparison between the Akaike information criteria (AIC) of our model specification and that of a hierarchical zero-inflated negative binomial model (due to the high number of zeros this could be a plausible model specification) suggested our model was a significantly better fit for the data.
} 
Table 2: Model Predicting the Absolute Number of Parliamentary Questions on Unemployment and Crime

\begin{tabular}{|c|c|c|c|c|}
\hline & \multicolumn{2}{|c|}{ Unemployment } & \multicolumn{2}{|c|}{ Crime } \\
\hline & Across district & Across Time & Across district & Across Time \\
\hline Intercept & $-4.57 * * *(0.67)$ & $-4.78 * * *(0.67)$ & $-2.81 * * *(0.59)$ & $-2.76^{* * *}(0.60)$ \\
\hline Problem pressure & $0.04(0.12)$ & $0.02 * * *(0.00)$ & $0.31 *(0.12)$ & $0.01(0.01)$ \\
\hline Magnitude(log) & $-0.26(0.18)$ & $-0.22(0.17)$ & $-0.64 * * *(0.16)$ & $-0.65^{* * *}(0.16)$ \\
\hline Mandates in district & $0.02(0.07)$ & $-0.01(0.07)$ & $0.07(0.06)$ & $0.06(0.06)$ \\
\hline Vulnerability & $0.12(0.19)$ & $0.18(0.19)$ & $0.16(0.20)$ & $0.08(0.20)$ \\
\hline Female MP & $0.33(0.33)$ & $0.32(0.32)$ & $0.26(0.29)$ & $0.30(0.29)$ \\
\hline Opposition & $1.66 * * *(0.29)$ & $1.73 * * *(0.29)$ & $1.47 * * *(0.20)$ & $1.51 * * *(0.20)$ \\
\hline MP localness & $0.66(0.34)$ & $0.64(0.34)$ & $0.89 * *(0.30)$ & $0.94 * *(0.30)$ \\
\hline Committee & $0.24 * *(0.09)$ & $0.23 * *(0.08)$ & $0.53 * * *(0.11)$ & $0.54 * * *(0.11)$ \\
\hline $\mathrm{BE}$ & $3.94 * * *(0.52)$ & $3.83 * * *(0.52)$ & $2.39 * * *(0.51)$ & $2.56 * * *(0.51)$ \\
\hline CDS-PP & $1.65 * * *(0.50)$ & $1.57 * *(0.50)$ & $1.84 * * *(0.43)$ & $1.94 * * *(0.44)$ \\
\hline PCP & $4.54 * * *(0.49)$ & $4.50 * * *(0.49)$ & $3.75 * * *(0.47)$ & $3.89 * * *(0.48)$ \\
\hline PSD & $0.46(0.38)$ & $0.40(0.38)$ & $0.27(0.32)$ & $0.33(0.32)$ \\
\hline \multicolumn{5}{|l|}{ Random Effects } \\
\hline$\tau_{00}$ & $2.05_{\text {individual } \mathrm{MP}}$ & 2.07 individual MP & $2.00_{\text {individual MP }}$ & $2.09_{\text {individual }} \mathrm{MP}$ \\
\hline \# groups & 342 individual MP & $341_{\text {individual MP }}$ & $345_{\text {individual MP }}$ & $345_{\text {individual MP }}$ \\
\hline Observations & 1249 & 1240 & 1265 & 1265 \\
\hline AIC & 1201.811 & 1178.073 & 1529.537 & 1535.586 \\
\hline
\end{tabular}

Note: Dependent variable: absolute number of questions about unemployment and criminal issues asked in the $11^{\text {th }}$ and $12^{\text {th }}$ legislatures of the Portuguese Assembleia da Republica.

Model: Hierarchical negative binomial regression. Standard errors in parentheses. Significance: $* \mathrm{p}<0.05, * * \mathrm{p}<0.01, * * * \mathrm{p}<0.001$ (two-tailed tests). $\tau 00$ is the random intercept variance, or betweensubject variance. AIC: Akaike information criterion.

\section{Results}

Starting from H1, Table 2 summarizes the results for the four specifications of our model (two issues times two operationalizations of problem pressure). Our main predictor, district-level problem pressure, points in the expected direction - the more severe the problem, the stronger the response of the MP - and is statistically significant both in the case of unemployment and crime issues. On the other hand, the results show that representatives seem to use two different logics to measure the severity of problems in the two areas. In the case of unemployment, it is the increase with respect to the previous year that positively affects the probability of questions being asked on the topic; in the case of crime, it is the difference with respect to the mean level of crime in the country. We speculate that this may originate from the different temporal dynamic of the two issues in the years under consideration (see Online Appendix $\mathrm{C}$ for an overview of trends on the two issues). The Euro crisis had a severe effect on unemployment across the country. All districts experienced a substantial increase in unemployment figures, which reached a peak around the first session of the XII legislature (2011-2012, namely the first year of the adjustment program signed with the Troika) and then progressively dropped. It was this temporal change that triggered a response of the representatives. Vice versa, crime indicators exhibit a more erratic pattern over time, with few noteworthy peaks. 
Turning to our control variables, as expected we find that being member of an opposition party, especially if it is a small opposition party like the PCP and the BE, is the strongest predictor of the number of questions submitted. Their MPs are generally more active and, lacking a voice in the government, give more value to the parliamentary question instrument. In addition, the cross-topic difference in the magnitude of coefficients for our party effects, to some extent, reflects our expectations based on issue ownership. Radical left-wing parties such as the BE and PCP are more active (higher coefficients) in the area of unemployment, whereas the right-wing CDS-PP is more dynamic in the area of crime.

Another consistent finding across topics and problem specifications is the positive and significant impact of committee membership (purged of the effect of district characteristics). Regardless of whether supply (MPs' preferences for a specific committee) or demand (party leaders' decisions) factors prevail in committee assignment, this result reveals that the division of policy portfolios within parliamentary parties is one of the main predictors of individual agendas (Louwerse and Otjes 2015; Waggoner 2019).

Also, we confirm previous findings showing that as district magnitude increases, the number of parliamentary questions decreases (although coefficients are statistically significant only for crime-related issues). Previous experience as local representatives in either a legislative or executive body in the district where they were elected influences MPs' decision to take up an issue only when looking at crime-related questions. On the contrary, spending many mandates as national representative of a district (mandates in district), the uncertainty of re-election (vulnerability) and gender do not seem to impact significantly on the number of questions. ${ }^{15}$

The effect of the political localness of MPs on responsiveness to problem pressure in the district (see Table 3) is never statistically significant at conventional levels. Whereas Fernandes et al. (2017) found that Portuguese MPs with previous experience in local government ask more district-related questions, we do not find that they signal to their constituents in response to problem pressure. As a test of the robustness of our findings, we tried narrower proxies of 'political localness', focusing only on whether the MP was either a member of a local executive or a mayor in a district municipality, but we still were not able to statistically eliminate the possibility that the observed relationship results were anything other than the result of pure chance.

Finally, our analysis partly corroborates H3 (see Table 4). We find a statistically significant and positive moderating impact of committee membership on the responsiveness to problem pressure, but it holds true only for crime. It shows that, within this committee, representatives elected in districts with higher crime rates ask more related questions.

\section{Conclusions}

This article examined whether and to what extent MPs can signal to their electoral district by sponsoring parliamentary questions on issues that might be considered problematic at

\footnotetext{
${ }^{15}$ To test the robustness of our findings, we applied the same model specifications to predict the number of policy-relevant parliamentary questions, although this time keeping only those questions making explicit reference to a geographic entity in the MP's district. We detected a reference in $34 \%$ of unemployment and $46 \%$ of crimerelated questions. The coding was done manually using the same coding rules applied by Fernandes et al. (2017: 679). The table of results in Online Appendix D reveals that the results are consistent, although the level of statistical significance dropped (probably due to the lower number of occurrences in the data set).
} 
Table 3: Model Predicting the Absolute Number of Parliamentary Questions on Unemployment and Crime testing $\mathrm{H} 2$

\begin{tabular}{|c|c|c|c|c|}
\hline & \multicolumn{2}{|c|}{ Unemployment } & \multicolumn{2}{|c|}{ Crime } \\
\hline & Across district & Across time & Across district & Across time \\
\hline Intercept & $-4.61 * * *(0.68)$ & $-4.79 * * *(0.67)$ & $-2.81 * * *(0.60)$ & $-2.75^{* * *}(0.60)$ \\
\hline Problem pressure & $-0.01(0.13)$ & $0.02 * * *(0.00)$ & $0.31 *(0.14)$ & $0.01(0.02)$ \\
\hline Magnitude(log) & $-0.27(0.18)$ & $-0.22(0.17)$ & $-0.64 * * *(0.16)$ & $-0.65 * * *(0.16)$ \\
\hline Mandates in district & $0.03(0.07)$ & $-0.00(0.07)$ & $0.07(0.06)$ & $0.06(0.06)$ \\
\hline Vulnerability & $0.13(0.19)$ & $0.18(0.19)$ & $0.16(0.20)$ & $0.08(0.20)$ \\
\hline Female MP & $0.33(0.33)$ & $0.33(0.32)$ & $0.26(0.29)$ & $0.30(0.29)$ \\
\hline Opposition & $1.66^{* * *}(0.29)$ & $1.73 * * *(0.29)$ & $1.47 * * *(0.20)$ & $1.51 * * *(0.20)$ \\
\hline MP localness & $0.64(0.34)$ & $0.66(0.35)$ & $0.90 * *(0.31)$ & $0.92 * *(0.31)$ \\
\hline Committee & $0.23 * *(0.09)$ & $0.23 * *(0.08)$ & $0.53 * * *(0.11)$ & $0.54 * * *(0.11)$ \\
\hline $\mathrm{BE}$ & $3.97 * * *(0.52)$ & $3.83^{* * *}(0.52)$ & $2.39 * * *(0.51)$ & $2.56 * * *(0.51)$ \\
\hline CDS-PP & $1.65 * *(0.51)$ & $1.57 * *(0.50)$ & $1.83 * * *(0.43)$ & $1.94 * * *(0.44)$ \\
\hline PCP & $4.57 * * *(0.50)$ & $4.50 * * *(0.49)$ & $3.75 * * *(0.47)$ & $3.89 * * *(0.48)$ \\
\hline PSD & $0.49(0.38)$ & $0.40(0.38)$ & $0.27(0.32)$ & $0.33(0.32)$ \\
\hline $\begin{array}{l}\text { Problem pressure* MP } \\
\text { localness }\end{array}$ & $0.21(0.27)$ & $-0.00(0.01)$ & $-0.03(0.28)$ & $-0.01(0.03)$ \\
\hline \multicolumn{5}{|l|}{ Random Effects } \\
\hline$\tau_{00}$ & $2.10_{\text {individual }} \mathrm{MP}$ & $2.07_{\text {individual }} \mathrm{MP}$ & $2.00_{\text {individual }} \mathrm{MP}$ & $2.09_{\text {individual MP }}$ \\
\hline \# groups & $342_{\text {individual MP }}$ & $341_{\text {individual MP }}$ & $345_{\text {individual MP }}$ & $345_{\text {individual MP }}$ \\
\hline Observations & 1249 & 1240 & 1265 & 1265 \\
\hline $\mathrm{AIC}$ & 1203.227 & 1180.021 & 1531.524 & 1537.424 \\
\hline
\end{tabular}

Note: Dependent variable: absolute number of questions about unemployment and criminal issues asked in the $11^{\text {th }}$ and $12^{\text {th }}$ legislatures of the Portuguese Assembleia da Republica.

Model: Hierarchical Negative Binomial regression. Standard errors in parentheses. Significance: $* p<0.05, * * p<0.01, * * * p<0.001$ (two-tailed tests). $\tau 00$ is the random intercept variance, or betweensubject variance. AIC: Akaike information criterion.

the local level. It focused on Portugal, a country in which an MP's chances of re-election depend greatly on the decisions of party elites, so the dyadic relationship between MPs and their constituencies should be less likely. On the other hand, as Fernandes et al. (2017) and Zittel et al. (2019) suggest, some form of constituency service may still bring electoral pay-offs for the party even in countries characterised by a non-preferential electoral system, and strategic leaders should be eager to leverage the local ties and visibility of their MPs as a means of strengthening the party label. Additionally, previous studies on Portugal had already detected evidence of behaviour with a constituency focus (e.g. time spent in the district), especially by MPs elected in smaller districts (Pilet et al. 2012). This study has sought to innovate with respect to past analyses by testing whether district characteristics are factored in by MPs at the moment of deciding the topic of their parliamentary questioning.

We provided evidence that, at least as far as the two selected issues are concerned, Portuguese MPs do perform substantive representation of their own constituency by signalling effort through parliamentary questions. District-specific problem pressure, measured as variation in crime and unemployment statistics, is associated with a greater propensity of the MP to focus on the issue through sponsored parliamentary questions. This is an interesting finding that contributes new knowledge to the ongoing debate on the 
Table 4: Model Predicting the Absolute Number of Parliamentary Questions on Unemployment and Crime testing $\mathrm{H} 3$

\begin{tabular}{|c|c|c|c|c|}
\hline & \multicolumn{2}{|c|}{ Unemployment } & \multicolumn{2}{|c|}{ Crime } \\
\hline & Across district & Across time & Across district & Across time \\
\hline Intercept & $-4.57 * * *(0.67)$ & $-4.76^{* * *}(0.67)$ & $-2.63 * * *(0.58)$ & $-2.76^{* * *}(0.60)$ \\
\hline Problem pressure & $0.04(0.12)$ & $0.02 * * *(0.00)$ & $0.30 *(0.12)$ & $0.01(0.01)$ \\
\hline Magnitude(log) & $-0.26(0.18)$ & $-0.22(0.17)$ & $-0.63 * * *(0.15)$ & $-0.65 * * *(0.16)$ \\
\hline Mandates in district & $0.02(0.07)$ & $-0.00(0.07)$ & $0.04(0.06)$ & $0.06(0.06)$ \\
\hline Vulnerability & $0.12(0.19)$ & $0.17(0.19)$ & $0.10(0.19)$ & $0.09(0.20)$ \\
\hline Female MP & $0.33(0.33)$ & $0.33(0.32)$ & $0.24(0.28)$ & $0.30(0.29)$ \\
\hline Opposition & $1.66^{* * *}(0.29)$ & $1.73 * * *(0.29)$ & $1.45^{* * *}(0.19)$ & $1.51 * * *(0.20)$ \\
\hline MP localness & $0.66(0.34)$ & $0.64(0.34)$ & $0.84 * *(0.29)$ & $0.94 * *(0.30)$ \\
\hline Committee & $0.24 * *(0.09)$ & $0.20 *(0.08)$ & $0.38 * * *(0.11)$ & $0.55^{* * *}(0.11)$ \\
\hline $\mathrm{BE}$ & $3.94 * * *(0.52)$ & $3.83^{* * *}(0.52)$ & $2.28 * * *(0.49)$ & $2.57 * * *(0.51)$ \\
\hline CDS-PP & $1.65^{* * *}(0.50)$ & $1.57 * *(0.50)$ & $1.77 * * *(0.42)$ & $1.94 * * *(0.44)$ \\
\hline PCP & $4.54 * * *(0.49)$ & $4.49 * * *(0.49)$ & $3.76^{* * *}(0.45)$ & $3.89 * * *(0.48)$ \\
\hline PSD & $0.46(0.38)$ & $0.40(0.38)$ & $0.21(0.31)$ & $0.33(0.32)$ \\
\hline $\begin{array}{l}\text { Problem pressure* } \\
\text { Committee }\end{array}$ & $0.00(0.07)$ & $0.00(0.00)$ & $0.31 * *(0.09)$ & $0.00(0.01)$ \\
\hline \multicolumn{5}{|l|}{ Random Effects } \\
\hline$\tau_{00}$ & $2.05_{\text {individual } \mathrm{MP}}$ & $2.07_{\text {individual }} \mathrm{MP}$ & $1.85_{\text {individual MP }}$ & $2.09_{\text {individual }} \mathrm{MP}$ \\
\hline \# groups & $342_{\text {individual MP }}$ & $341_{\text {individual MP }}$ & $345_{\text {individual MP }}$ & $345_{\text {individual MP }}$ \\
\hline Observations & 1249 & 1240 & 1265 & 1265 \\
\hline AIC & 1203.811 & 1179.084 & 1520.304 & 1537.524 \\
\hline
\end{tabular}

Note: Dependent variable: absolute number of questions about unemployment and criminal issues asked in the $11^{\text {th }}$ and $12^{\text {th }}$ legislatures of the Portuguese Assembleia da Republica.

Model: Hierarchical Negative Binomial regression. Standard errors in parentheses. Significance: ${ }^{*} \mathrm{p}<0.05, * * \mathrm{p}<0.01, * * * \mathrm{p}<0.001$ (two-tailed tests). $\tau 00$ is the random intercept variance, or betweensubject variance. AIC: Akaike information criterion.

factors accounting for the representative relationship between MPs and constituents, particularly with regard to the impact of district-level characteristics (Däubler 2018). Furthermore, we detect evidence of this constituency link in a least-likely country case, Portugal, which leads us to expect stronger or, at least, similar patterns in political systems using preferential electoral systems. On the other hand, the evidence is less conclusive on whether this effect is conditioned on political localness or committee membership. Further studies are warranted on the microlevel foundations of the patterns observed in the present analysis.

Another consistent finding in our analysis is the influence of committee membership on an MP's decision to take up an issue, which suggests the importance of the division of labour and policy specialization within Portuguese parliamentary groups. Interestingly, these results are concordant with those on the MP-constituency relationship in a different legislature, the US Congress, leading the author to conclude that "while constituents may play a role, at best it seems that it is an indirect and mixed one, with institutional factors such as committee membership being a much more consistent driver of issue sponsorship" (Waggoner 2019: 732).

Future research should address the limitations of this study by expanding the time interval, looking at different signalling instruments (e.g. bill sponsorship) as well as 
integrating the insights of large- $\mathrm{N}$ analysis with qualitative data on the motivations driving the agenda decisions of MPs. Furthermore, the increasing availability of large data sets coding the policy content of parliamentary behaviour (e.g. Borghetto and ChaquesBonafont 2019) should pave the way for testing whether the finding on the influence of district problem pressure for patterns of issue sponsorship holds across different institutional configurations and policy areas.

\section{Acknowledgements}

Earlier versions of the manuscript were presented at the ECPR General Conference 2017 in Oslo and the ECPR Joint Sessions 2018 in Nicosia. The authors are grateful to the participants in these events, as well as the editors of the Special Issue and reviewers for their helpful comments. This article was financially supported through Portuguese funds by the Fundação para a Ciência e a Tecnologia within the scope of the Strategic Financing of the R\&D Unit UID/SOC/03126/2019, the PTDC/IVC-CPO/3921/2012 project, the IF/00382/2014 FCT Investigator Contract and the PTDC /IVC-C PO/3098/ 2014 project. The data and script allowing to replicate the analyses presented in this article are publicly available in the SPSR website as online supplementary material.

\section{References}

Andeweg, R. B. and J. Thomassen (2011). Pathways to Party Unity: Sanctions, Loyalty, Homogeneity and Division of Labour in the Dutch Parliament. Party Politics 17(5): 655-672.

André, A., S. Depauw and K. Deschouwer (2014a). Legislators' Local Roots: Disentangling the Effect of District Magnitude. Party Politics 20(6): 904-917.

André, A., S. Depauw, M. Shugart (2014b). The Effect of Electoral Institutions on Legislative Behaviour. In Martin, S. et al. (eds), The Oxford Handbook of Legislative Studies. Oxford; New York: Oxford University Press (231-249).

André, A., S. Depauw and S. Martin (2015). Electoral Systems and Legislators' Constituency Effort The Mediating Effect of Electoral Vulnerability. Comparative Political Studies 48(4): 464-496.

Belchior, A. M. and E. Borghetto (2019). The Portuguese Policy Agendas Project. In Baumgartner, F. R., C. Breunig and E. Grossmann (eds.), Comparative Policy Agendas: Theory, Tools, Data. Oxford: Oxford University Press (145-151).

Bertelli, A. M. and R. M. Dolan (2009). The Demand and Supply of Parliamentary Policy Advocacy: Evidence from UK Health Policy, 1997-2005. Government and Opposition 44(3): 219242.

Bevan, S. and P. John (2016). Policy Representation by Party Leaders and Followers: What Drives UK Prime Minister's Questions? Government and Opposition 51(1): 59-83.

Bird, K. (2005). Gendering Parliamentary Questions. The British Journal of Politics and International Relations 7(3): 353-370.

Birkland, T. A. (1998). Focusing Events, Mobilization, and Agenda Setting. Journal of Public Policy 18(1): 53-74.

Blidook, K. and M. Kerby (2011). Constituency Influence on 'Constituency Members': The Adaptability of Roles to Electoral Realities in the Canadian Case. The Journal of Legislative Studies 17(3): 327-339.

Borghetto, E. and L. Chaques-Bonafont (2019). Parliamentary Questions. In Baumgartner, F. R., C. Breunig and E. Grossmann (eds.), Comparative Policy Agendas: Theory, Tools, Data. Oxford, New York: Oxford University Press (282-299). 
Borghetto, E. and M. Lisi (2018). Productivity and Reselection in a Party-Based Environment: Evidence from the Portuguese Case. Parliamentary Affairs 71(4): 868-887.

Carey, J. M. (2007). Competing Principals, Political Institutions, and Party Unity in Legislative Voting. American Journal of Political Science 51(1): 92-107.

Carey, J. M. and M. Shugart (1995). Incentives to Cultivate a Personal Vote: A Rank Ordering of Electoral Formulas. Electoral Studies 14(4): 417-439.

Däubler, T. (2018). National Policy for Local Reasons: How MPs Represent Party and Geographical Constituency through Initiatives on Social Security. Acta Politica. Advanced online: https://doi. org/10.1057/s41269-018-0125-x [accessed 7.1.2019].

Fernandes, J. M., L. Geese and C. Schwemmer (2019). The Impact of Candidate Selection Rules and Electoral Vulnerability on Legislative Behaviour in Comparative Perspective. European Journal of Political Research 58(1): 270-291.

Fernandes, J. M., C. Leston-Bandeira and K. Schwemmer (2017). Election Proximity and Representation Focus in Party-Constrained Environments. Party Politics 24(6): 674-685.

Fowler, A. and M. Margolis (2014). The Political Consequences of Uninformed Voters. Electoral Studies 34(June): 100-110.

Freire, A., M. Lisi, I. Andreadis and J. M. L. Viegas (2017). Political Representation in Times of Bailout: Evidence from Greece and Portugal. Routledge.

Itzkovitch-Malka, R. and R. Y. Hazan (2017). Unpacking Party Unity: The Combined Effects of Electoral Systems and Candidate Selection Methods on Legislative Attitudes and Behavioural Norms. Political Studies 65(2): 452-474.

Jensen, C. B., S.-O. Proksch and J. B. Slapin (2013). Parliamentary Questions, Oversight, and National Opposition Status Inthe European Parliament. Legislative Studies Quarterly 38(2): 259282.

Kellermann, M. (2013). Sponsoring Early Day Motions in the British House of Commons as a Response to Electoral Vulnerability. Political Science Research and Methods 1(2): 263-280.

- (2016). Electoral Vulnerability, Constituency Focus, and Parliamentary Questions in the House of Commons. The British Journal of Politics and International Relations 18(1): 90-106.

Krehbiel, K. (1991). Information and Legislative Organization. Ann Arbor: University of Michigan.

Leston-Bandeira, C. (2004). From Legislation to Legitimation: The Role of the Portuguese Parliament. London and New York: Taylor \& Francis.

- (2009). Dissent in a Party-Based Parliament The Portuguese Case. Party Politics 15(6): 695-713. Leston-Bandeira, C. and A. Freire (2003). Internalising the Lessons of Stable Democracy: The Portuguese Parliament. The Journal of Legislative Studies 9(2): 56-84.

Lipset, S. M. and S. Rokkan (1967). Cleavage Structures, Party Systems and Voter Alignments: An Introduction. In Lipset, S. M. and S. Rokkan (eds.), Party Systems and Voter Alignments. New York: The Free Press (1-64).

Lisi, M. (2015). Party Change, Recent Democracies, and Portugal: Comparative Perspectives. Lanham, Maryland: Lexington Books.

Lisi, M. and J. Santana-Pereira (2014). Campaign Individualisation before and after the Bailout: A Comparison between Greece and Portugal. South European Society and Politics 19(4): 541-559.

Louwerse, T. and S. Otjes (2015). The Impact of Parliamentary Specialisation on Cosponsorship. The Journal of Legislative Studies 21(4): 476-494.

(2016). Personalised Parliamentary Behaviour without Electoral Incentives: The Case of the Netherlands. West European Politics 39(4): 778-799.

Mair, P. (2013). Ruling The Void: The Hollowing Of Western Democracy. London; New York: Verso. Mansbridge, J. (2003). Rethinking Representation. American Political Science Review 97(4): 515-528. 
Martin, S. (2011). Using Parliamentary Questions to Measure Constituency Focus: An Application to the Irish Case. Political Studies 59(2): 472-488.

- (2014). Committees. In Martin, S., T. Saalfeld and K. Strøm (eds.), The Oxford Handbook of Legislative Studies. Oxford; New York: Oxford University Press (352-370).

Pilet, J.-B., A. Freire and O. Costa (2012). Ballot Structure, District Magnitude and ConstituencyOrientation of MPs in Proportional Representation and Majority Electoral Systems. Representation 48(4): 359-372.

Proksch, S.-O. and J. B. Slapin (2010). Position Taking in European Parliament Speeches. British Journal of Political Science 40(3): 587-611.

Robertson, D. B. (1976). A Theory of Party Competition. London: John Wiles \& Sons.

Russo, F. (2011). The Constituency as a Focus of Representation: Studying the Italian Case through the Analysis of Parliamentary Questions. The Journal of Legislative Studies 17(3): 290-301.

Saalfeld, T. (2011). Parliamentary Questions as Instruments of Substantive Representation: Visible Minorities in the UK House of Commons, 2005-10. The Journal of Legislative Studies 17(3): 271289.

Saalfeld, T. and D. Bischof (2013). Minority-Ethnic MPs and the Substantive Representation of Minority Interests in the House of Commons, 2005-2011. Parliamentary Affairs 66(2): 305-328.

Seguro, A. J. M. (2016). A Reforma Do Parlamento Português. Lisbon: Quetzal Editores.

Shugart, M. S., M. E. Valdini and K. Suominen (2005). Looking for Locals: Voter Information Demands and Personal Vote-Earning Attributes of Legislators under Proportional Representation. American Journal of Political Science 49(2): 437-449.

Soroka, S., E. Penner and K. Blidook (2009). Constituency Influence in Parliament. Canadian Journal of Political Science/Revue Canadienne de Science Politique 42(3): 563-591.

Strøm, K. (1997). Rules, Reasons and Routines: Legislative Roles in Parliamentary Democracies. The Journal of Legislative Studies 3(1): 155-174.

Syrett, S. (2017). Contemporary Portugal: Dimensions of Economic and Political Change. London; New York: Routledge.

Teixeira, C. P., A. Freire and A. M. Belchior (2012). Parliamentary Representation in Portugal: Deputies' Focus and Style of Representation. Portuguese Journal of Social Science 11(2): 99-117.

Vliegenthart, R., S. Walgrave, F. R. Baumgartner, S. Bevan, C. Breunig, S. Brouard, L. C. Bonafont, et al. (2016). Do the Media Set the Parliamentary Agenda? A Comparative Study in Seven Countries. European Journal of Political Research 55(2): 283-301.

Waggoner, P. D. (2019). Do Constituents Influence Issue-Specific Bill Sponsorship? American Politics Research 47(4): 709-738.

Wlezien, C. (2005). On the Salience of Political Issues: The Problem with 'Most Important Problem'. Electoral Studies 24(4): 555-579.

Zittel, T., D. Nyhuis and M. Baumann (2019). Geographic Representation in Party-Dominated Legislatures: A Quantitative Text Analysis of Parliamentary Questions in the German Bundestag. Legislative Studies Quarterly 44(4): 681-711.

\section{Supporting Information}

Additional Supporting Information may be found in the online version of this article: 
Enrico Borghetto is a senior researcher at the Portuguese Institute for International Relations and the Interdisciplinary Centre of Social Science of the Nova University of Lisbon. His research has focused on compliance with EU policies, the Europeanisation of national legislation, legislative and agenda-setting studies. Email: enrico.borghetto@fcsh.unl.pt

José Santana-Pereira (PhD in Political and Social Sciences, EUI) is an Assistant Professor at the Department of Political Science and Public Policy, ISCTE-Lisbon University Institute, and Researcher at CIES-Lisbon University Institute. His research focuses on media systems, media effects on public opinion, campaigns, political attitudes and voting behaviour. E-mail: jose.santana.pereira@iscte-iul.pt

André Freire is Full Professor in Political Science at ISCTE-IUL (University Institute of Lisbon) and also senior researcher at CIES-IUL (Centre for Sociological Studies and Research). He has published about political representation, political institutions, ideology and mass' and elite's attitudes and behaviour. E-mail: andre.freire@iscte-iul.pt 